\title{
Improvement of NOx-PM Trade-off in CIE Though Blends of Ethanol or Methanol and EGR
}

\author{
Miqdam Tariq Chaichan \\ Assistant Professor, Mechanical Engineering Department, University of Technology, Baghdad, Iraq
}

\begin{abstract}
The reduction of greenhouse gas emissions is a demand for the solid contribution replacement of oil-derived transportation fuels with alternatives as ethanol and methanol. Exhaust gas recirculation (EGR) is from the most effective techniques for reducing NOx emissions in compression ignition engines. A 4-cylinder four stroke water cooled direct injection (DI) Fiat diesel engine used for conducting tests with (10\% ethanol or $10 \%$ methanol) oxygenates blends with diesel fuel combined with EGR technique. The study focused on the trade-off between NOx and PM. The results show that the PM concentration decreases regardless of the types of oxygenating additives, and it decreases with the increase of the oxygen mass fraction in the blends without increasing the NOx. The emitted PM concentrations from diesel engine increased when fuelled with pure diesel fuel and equipped with EGR. Engine operation on the diesel- oxygenate blends presents a remarkable reduction in NOx/ PM concentrations.
\end{abstract}

Keywords: NOx-PM trade-off, methanol, ethanol, EGR.

\section{INTRODUCTION}

The oil shortage and environmental protection increase the concerns of future energy and environment conditions. The research works by enhancing the fuel economy and decreasing the emitted exhaust emissions have become the principal target of the engine development combustion criteria. As a result, the engines alternative fuels attracted an increasing attention. Compared to diesel and gasoline, the alternative fuels considered have exemplary combustion processes [1]. The increased usage of these alternative fuels has an advantage in slowing down the fossil fuels consumption and reducing emitted exhaust emissions [2]. Methanol and ethanol can consider among these fuels.

Methanol $\left(\mathrm{CH}_{3} \mathrm{OH}\right)$ and Ethanol $\left(\mathrm{C}_{2} \mathrm{H}_{5} \mathrm{OH}\right)$ are quite similar products. Both are liquid homogeneous alcohols with a simple chemical structure and used as motor fuels. They can be used as neat fuels or blended with gasoline or diesel [3]. The simplest of alcohol is Methanol, $\mathrm{CH}_{3} \mathrm{OH}$ that produced by the wood destructive distillation. Today, methanol produced in huge quantities from natural gas using the gas reformation process. In this process, the carbon monoxide and hydrogen pass (under favourable conditions of temperature and pressure) over a suitable catalyst [4]. Methanol as a substance is a clear, colourless, and high-performance liquid fuel. It is suitable as a fuel in both spark-ignition and diesel engines. Methanol burns as a neat $(100 \%$ methanol) or as a blend with other fuels in internal combustion engines. The most common type of methanol employed in light-duty vehicles is a mixture of $85 \%$ methanol and $15 \%$ gasoline called M85. Neat methanol, M100, is applying in some buses and heavyduty trucks [5].

Ethanol, which has the molecular formula $\mathrm{C}_{2} \mathrm{H}_{5} \mathrm{OH}$, is also called ethyl alcohol, grain alcohol, or just alcohol. Pure Ethanol as a liquid characterized as it is a colourless, flammable, and has a boiling point at $78.5^{\circ} \mathrm{C}$. Ethanol is toxic, affecting the central nervous system [6]. Ethanol provided minor reductions in produced brake power and increased of brake specific fuel consumption. Ethanol brings the flash point of the fuel down below the diesel fuel legal limit. The cetane rating of ethanol is low; as a result, the ethanol-diesel blends require a cetane improver addition to achieving the adequate fuel performance. Ethanol and diesel blend suspension needs a cetane number improver and an emulsifier that add expenses to the cost of the fuel [7].

Methanol and ethanol complement each other. The ICE performance and emissions when fuelled with any of the two alcohols are quite similar. Ethanol divers from methanol that it has not a flame visibility issue, because ethanol creates the yellow colour when it burns due to its two carbon molecules. However, ethanol also has much lower vapour pressure than methanol (2.3 psi compared to 4.6 psi for methanol), which means a more difficult cold starting. Both alcohols have a high latent heat of vaporization and a single boiling point that cause the cold start problems, particularly, at temperatures much below 8 ${ }^{\circ} \mathrm{C}$. Ethanol as an alcohol fuel is the choice for transportation use because its volumetric energy density is better than methanol, which increases the board energy storage of the fuel [8].

The ignition quality of fuel, defined by its cetane number, affects the delay. The cetane number is a function of a fuel's molecular structure. Straight-chain paraffinic compounds (normal alkenes) have the highest ignition quality, which improves as the chain length increases. Aromatic compounds have poor ignition quality as do alcohols. (Certain difficulties are connected with the use of the potential alternative fuels methanol and ethanol in compression-ignition engines [9].

In the diesel engine, the simultaneous reduction of NOx and smoke is difficult due to the trade-off relationship between NOx and PM. The oxygenated alternative fuels can consider as one possible method to solve this obstacle due to the more oxygen addition from the oxygenated fuels during combustion. This procedure can decrease the 
engine emissions without considerable modification of the diesel engine and has a wide applicability in currently used vehicle [10].

Exhaust gas recirculation (EGR) employment in diesel engines is to achieve the NOx concentrations reductions. EGR technique proved that it is an effective one in reducing the NOx emissions from the diesel engine exhaust [11]. As the name implies, EGR involves recalculating a part of the engine's exhaust gasses back to the intake manifold in naturally aspirated engines case. Controlling the NOx emissions requires reduction of incylinder temperatures [12]. However, the EGR application increases the fuel consumption and emission penalties. Also, EGR employment increases the emitted $\mathrm{HC}, \mathrm{CO}$, and PM concentrations [13].

In most systems, the temperature of the recalculated gasses lowered using an intercooler. The cooled recalculated gasses have a higher heat capacity and lower oxygen compared to air. The resulted lower combustion temperature due to EGR utilization inhibits the NOx formation. Diesel particulate filters used with a lowpressure EGR system to prevent the large amounts of particulate matter from recalculating back to the engine. EGR systems are able of reducing NOx emissions by more than $40 \%$ [14].

EGR rates are suitable for high engine load. Besides, as the engine load increases; the generation of more PM of the diesel engines tend happens due to the oxygen reduction. Therefore, although EGR is effective in NOx reduction, it increases the PM concentrations [15]. Ref. 16 performed many tests on a single cylinder DI diesel engine and evaluated the engine performance and emission characteristics when it fuelled with the rice bran methyl ester (RBME) and its blends with an EGR system. They reported that a $20 \%$ biodiesel blends with $15 \%$ EGR produced the least $\mathrm{NOx}, \mathrm{CO}$, and $\mathrm{HC}$ emissions and improved the thermal efficiency, also [16].

A similar dual fuel engine fuelled with oxygenated fuel and assisted by a small amount of gas oil was tested. The tests confirmed a significant enhancement in the NOx-PM trade-off achieved without thermal efficiency decrease by employing a minimum quantity of gas oil for stable ignition and EGR [17, 18 \& 19].

Ogawa et al. and $\mathrm{Li}$ et al. tested the smoke emission experimentally, and they declared that it could decrease drastically in case of using large quantities of cooled EGR with low cetane number fuels. Also, the smoke depends strongly on the ignition delay period, which represents the available premixing time between the fuel injection end and the ignition start. This low emission could achieve by a low-temperature combustion relies on the ultra-high EGR ratio addition [20, $21 \& 22]$.

Up to now, the reports on the oxygenate additives in diesel engine utilization has a lack the comprehensive studies of combustion and emitted emissions. The general behaviours of the oxygenate addition to diesel in the engine combustion have not clarified yet, resulting in difficulties in guiding the selection of oxygenates and the engine operation and [23]. From this point of view, the objectives of this study are to investigate the NOx-PM emissions trade-off behavior in a multi cylinders compression-ignition engine operating on various types of diesel-oxygenate blends with variable dilution rates.

\section{EXPERMINTAL WORK}

Materials

The used blends (diesel/10\% ethanol and diesel/ 10\% methanol) were chosen based on prior works of many researchers. These works demonstrated that these blends produce the best engine performance with the lower emissions.

Commercial diesel fuel and ethanol (99.7\% purity) used in this work. The ethanol-diesel blended fuel formed by blending the following components: diesel fuel, ethanol, cetane number improver, and solvent. The first process to blend procedure preparation is blending the cetane number improver and solvent $(1.5 \% \mathrm{v} / \mathrm{v}$ for all ethanol-diesel blended fuel) into the ethanol, and then blend this mixture into the diesel fuel.

Therefore, some basic properties of $10 \%$ ethanol-diesel blended fuel measured. Lower heat values, carbon content, and oxygen content of blended fuel calculated. The fuel density evaluated by weighing a known volume of oil; the oil viscosity measured by a dynamic viscometer. The measurement procedure consisted of quantifying the needed time for oil known volume to drop from a viscometer. The flash point measured using a close-up method; the fuels surface tension measured by a surface tension meter. The previous measures (oil density, surface tension, and liquid viscosity) measured at $20^{\circ} \mathrm{C}$. All the measurements were repeated at least three times, and Table 1 lists the average results.

Diesel with $10 \%$ methanol blend selected for the recent study. Due to the low methanol solubility in the diesel fuel, a solvent consisting of oleic and iso-butanol added to the blend to enhance the stability of the blend. Fuel properties and the constitutions of the blend given in Table 1 , and the oxygen fraction in the fuel blends was about 8.52 as shown in Table 1. The oxygen in the fuel blends came mainly from added methanol, although the mass fractions of methanol and solvent have the same level. So, it is reasonable to consider the impact of oxygen in the fuel blends to be from the addition of methanol. The fuel properties in Table 1 demonstrate that methanol has high oxygen content while it has a low heating value and cetane number compared to diesel fuel.

TABLE I: FUEL PROPERTIES FOR DIESEL AND ETHANOL

\begin{tabular}{|l|c|c|c|}
\hline \multicolumn{1}{|c|}{ specification } & Diesel & Ethanol & Methanol \\
\hline Chemical formula & $\mathrm{C}_{10.8} \mathrm{H}_{18.7}$ & $\mathrm{C}_{2} \mathrm{H}_{5} \mathrm{OH}$ & $\mathrm{CH}_{3} \mathrm{OH}$ \\
\hline Mole weight $(\mathrm{g})$ & 148.3 & 46.1 & 32 \\
\hline Density $\left(\mathrm{g} / \mathrm{cm}^{3}\right.$ at $\left.20^{\circ} \mathrm{C}\right)$ & 0.84 & 0.789 & 0.828 \\
\hline Boiling point $\left({ }^{\circ} \mathrm{C}\right)$ & $180-330$ & 78 & 0.796 \\
\hline Heat of evaporation $(\mathrm{kJ} / \mathrm{kg})$ & 280 & 856 & 1110 \\
\hline Lower heat value $(\mathrm{MJ} / \mathrm{kg})$ & 42.5 & 27.0 & 19.68 \\
\hline Liquid viscosity $\left(\mathrm{cP}\right.$ at $\left.20^{\circ} \mathrm{C}\right)$ & 3.03 & 1.2 & 1.07 \\
\hline $\begin{array}{l}\text { Surface tension }(\mathrm{mN} / \mathrm{m} \text { at } \\
\left.20^{\circ} \mathrm{C}\right)\end{array}$ & 34.1 & 28.9 & 23.5 \\
\hline Flash point $\left({ }^{\circ} \mathrm{C}\right)$ & 78 & 13.5 & 11 \\
\hline Stoichiometric air fuel ratio & 14.4 & 9 & 6.4 \\
\hline Cetane number & 45 & $5-8$ & 2 \\
\hline Auto-ignition $\left({ }^{\circ} \mathrm{C}\right)$ & 235 & 423 & 588 \\
\hline Carbon content $(\mathrm{wt} \%)$ & 87.4 & 52.2 & 77.98 \\
\hline Oxygen content $(\mathrm{wt} \%)$ & 0 & 34.3 & 8.52 \\
\hline
\end{tabular}


The two prepared fuel blends with methanol and ethanol No direct measurements of PM size attempted (in this proportions fuelled the engine; meanwhile the NOx and study), due to a lack of suitable equipment. However, a PM concentrations measured and analyzed at the studied selection of particulate matter samples was obtained by engine load and speed. Furthermore, these emitted exposing filter material to a diesel exhaust gas at the end pollutants concentrations compared with those resulted of the tailpipe. These filters were examined using a from pure diesel combustion to clarify the impact of scanning electron microscope. An air sampler (low oxygenated additives on the burning.

\section{Experimental set up}

A four-cylinder, four strokes, direct injection, naturally aspirated diesel engine employed for the experiments. The engine specifications listed in Table 2. A hydraulic dynamometer attached to the engine, and the engine speed measured by a tacho-generator connected to the dynamometer.

\section{TABLE 2 : TESTED ENGINE SPECIFICATIONS}

\begin{tabular}{|l|l|}
\hline Engine type & 4cyl., 4-stroke \\
\hline Engine model & TD 313 Diesel engine rig \\
\hline Combustion type & DI, water cooled, natural aspirated \\
\hline Displacement & $3.666 \mathrm{~L}$ \\
\hline Valve per cylinder & two \\
\hline Bore & $100 \mathrm{~mm}$ \\
\hline Stroke & $110 \mathrm{~mm}$ \\
\hline Compression ratio & 17 \\
\hline Fuel injection pump & Unit pump \\
& 26 mm diameter plunger \\
\hline Fuel injection nozzle & Hole nozzle \\
& 10 nozzle holes \\
& Nozzle hole dia. $(0.48 \mathrm{~mm})$ \\
& Spray angle $=160^{\circ}$ \\
& Nozzle opening pressure $=40 \mathrm{MPa}$. \\
\hline
\end{tabular}

The engine's load and speed of adjusted by controlling the dynamometer resistance and the fuel pump injection rate. The engine fuel consumption measured by the level fuel decrease in a graduated container for a given period. An orifice plate used to measure the volumetric flow rate of the intake air. The exhaust gas temperature measured using a thermocouple type $\mathrm{K}$ connected to the exhaust manifold. Calibrated thermocouples used to measure the cooling water temperatures at the inlet and outlet of the engine.

The present study preferred the employment of an external EGR system. In this system, a piping used to route exhaust gas to the intake system. The EGR ratio considered as the ratio of the EGR to the aspired charge to the engine cylinder. The EGR ratio, in this study, calculated by the following equation:

$$
E G R=\frac{m_{E G R}}{\dot{m}_{\text {air }} \dot{+} \dot{m}_{E G R}}
$$

Where: $m_{\dot{E} G R}$ - is the mass flow rate of EGR air, and $\dot{m}_{\text {air }}$ - is the fresh air mass flow rate.

The EGR correct ratios calculation needs an exact definition of the EGR flow rate. However, this is a hard issue, due to the high temperature and the contamination of soot, ash, and unburned hydrocarbon.

The NOx concentrations measured using the Multigas mode 4880 emissions analyzer. The analyzer can detect the $\mathrm{CO}, \mathrm{CO}_{2}, \mathrm{HC}$ and $\mathrm{O}_{2}$ content. The exhaust gasses picked up from the engine exhaust pipe using a probe. They exhaust gasses separated from the water they contain employing the condensate separating filter, and then they conveyed in the measuring cell. volume), type Sniffer L-30, used for the collection of the emitted PMs. Filters type Whatmann-glass micro-filters used to collect emitted PMs. The filters weighted before and after the sampling process that extend for one hour. The equation determines the particulates matters concentrations:

$$
P M \text { in }\left(\mu g / m^{3}\right)=\frac{w_{2}-w_{1}}{V t} \times 10^{6}
$$

Where: $P M=$ the concentration of the particulate matters $\left(\mu \mathrm{g} / \mathrm{m}^{3}\right)$.

$w_{1}=$ the weight of the filter before sampling operation in $(\mathrm{g})$.

$w_{2}=$ the weight of the filter after the end of the sampling operation in $(\mathrm{g})$.

$V t=$ total trailed air volume $\left(\mathrm{m}^{3}\right), V t$ calculated by the equation:

$$
V t=Q_{t} \cdot t
$$

Where: $Q_{t}=$ the device elementary and final air flow rate $\left(\mathrm{m}^{3} / \mathrm{sec}\right)$.

$$
t=\text { the pattern time in (min). }
$$

Each filter preserved in a plastic bag until the collecting samples operation ended and the analyzing and studied process started.

\section{Experimental procedure}

Tests were done to evaluate the amount of PM and NOx generated utilizing different engine variables strategies as well as the fuel and EGR mode effects on these strategies. Experiments were initially carried out on the engine using neat diesel fuel to provide a baseline data. The engine warmed up for half an hour. Engine cooling water temperature maintained at $80^{\circ} \mathrm{C}$. Then, a $15 \%$ hot EGR used to appraise the effect of EGR on the NOx and PM concentrations. The EGR percentage selected as it is not a small percentage, so the dilution effect does not appear; on the other hand, it is not a high percentage to dominate the dilution effect.

The first set of tests conducted using $10 \%$ methanol blends (M10), and it followed the same above mentioned procedures. The second round of tests conducted using $10 \%$ ethanol blends (E10). Physical characteristics of the tested fuels listed in Table 1. These series of experiments carried out at an engine speed of $1500 \mathrm{rpm}$. The experiments performed at the designed injection timing of $38^{\circ}$ BTDC for all tested fuels. The third set of tests conducted to examine the injection timing (IT) effect. The IT varied from 20 to $45^{\circ}$ BTDC, each step of five degrees at constant $1500 \mathrm{rpm}$ engine speed and constant equivalence ratio.

In the last round of experiments, the engine speed varied starting from 1250 with intervals of $250 \mathrm{rpm}$ till the $2500 \mathrm{rpm}$. The engine operated at no load, medium load and full load. The fuel injection timing kept constant at $38^{\circ}$ BTDC with the variable speed tests. The fuel tank and fuel 
lines drained before each fuel test, and the engine ran at least 15 minutes to settle at the new blend. At every speed, the engine run for about five minutes to confirm the steady-state conditions, and then the data collected after that. Each test repeated at least three times and the average of these results considered.

\section{RESULTS and DISCUSSION}

Fig. 1 shows the NOx trends with EGR for variable engine loads. For all tested blends, NOx concentrations decrease with EGR existence. Compared to diesel fuel, the resulted NOx concentrations from M10 and E10 are higher. The rate of NOx reductions with EGR is much greater with oxygenated blends. Hence, oxygenated blends are more sensitive to EGR.

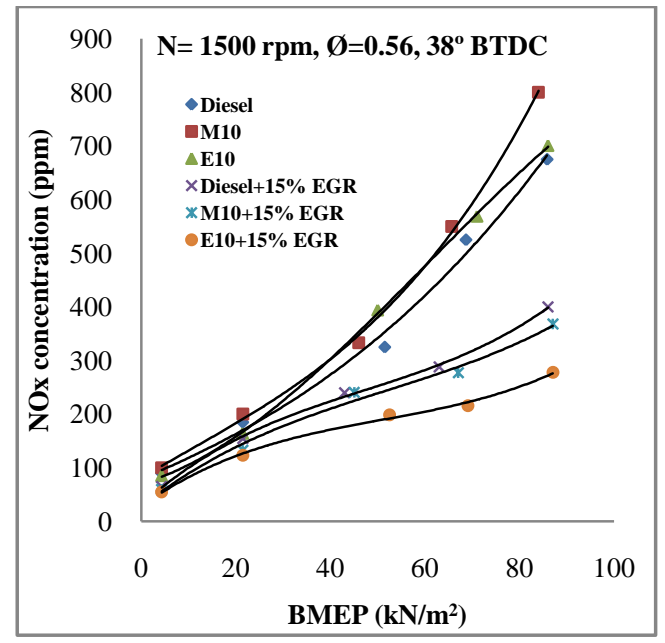

Fig. 1, load effect on NOx concentrations with and without EGR for tested blends

Published literature [24, $25 \& 26]$ quoted that three mechanisms by which the EGR impacts the combustion process, and hence the formation and reduction of NOx:

- Dilution Mechanism: The EGR's dilution effect causes a flame temperatures decrement that results in increasing mixing time and longer burn duration.

- Thermal Mechanism: The EGR-laced mixture increased heat capacity results in lowering the flame temperatures.

- Chemical mechanism: The EGR molecules (such as $\mathrm{CO}_{2}$ and $\mathrm{H}_{2} \mathrm{O}$ ) increase dissociation process that results in lowering the flame temperatures.

Oxygenated blends distinguished by low cetane numbers and long delay period. EGR addition intensified these properties, resulting in lower flame temperatures and hence lower NOx concentrations. This EGR effect appeared obviously with M10 utilization because it has the lowest cetane number. EGR caused about 36.27\%, 56.22 and $43.59 \%$ for diesel, M10 and E10 respectively.

Fig. 2 illustrates the measured PM for the tested fuels with variable loads. EGR caused the PM concentrations of diesel fuel to increase by about $17 \%$. The dilution mechanism affects the flame temperatures and frustrated combustion. The figure shows that PM emission for diesel increases with EGR addition for different torques. This significant increase in PM is due to:
- EGR reduces the overall air/fuel ratio, as a result, enhances the particulates increase.

- Recirculated exhaust gasses contain particulates that contribute to increasing the smoke level.

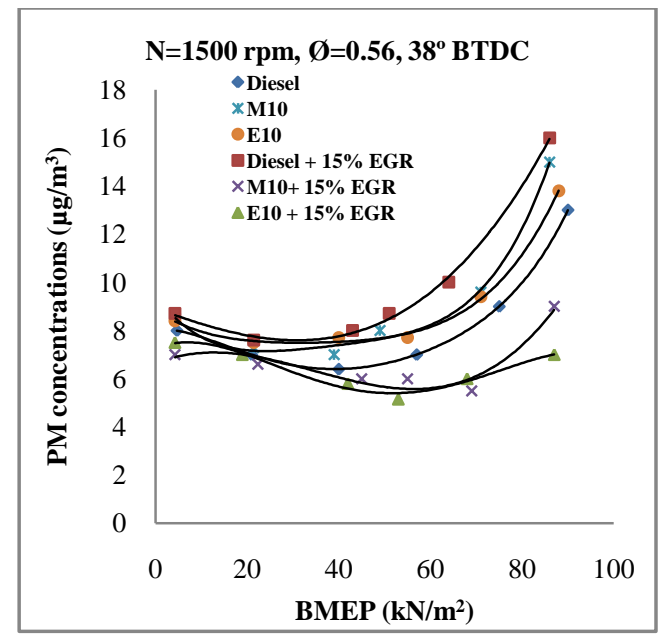

Fig. 2, load effect on PM concentrations with and without EGR for tested blends

Ethanol and methanol addition increased oxygen content inside the combustion chamber, and preserved combustion efficiency, causing PM concentrations to be reduced by $20.43 \%$ and $29.44 \%$ for M10 and E10 respectively. The reduction is higher with E10 due to its higher oxygen content.

Ref. 10 concluded that the PM concentration decreases with the oxygen mass fraction increase in the blends, and this trend is evident at high engine loads. Adding oxygenates to diesel fuel can reduce the engine's smoke due to the promotion of post-flame oxidation of PM and the improvement of the diffusive combustion in the late expansion and exhaust processes. By increasing the blend's oxygen mass fraction by ten percent, it can decrease the engine PM by $30-40 \%$.

The effect of engine speed on NOx concentrations for three load conditions: no load (fig. 3), medium load (fig. 4) and high load (fig. 5) studied with EGR usage. The figures show that increasing load increase NOx concentrations, also increasing speed increase these concentrations. Adding oxygenates increased NOx for medium and high speeds. The mechanisms associated with NOx formation and destruction strongly depend on flame temperature. Besides, high concentrations of oxygen and nitrogen must present so the NOx formation can occur. The diesel engine combustion provides both these essential conditions, as well as, adding oxygenates improves this trend.

The reduction in NOx concentrations with EGR at no load conditions are less in comparison with high load conditions. In high load conditions, the in-cylinder temperatures change noticeably by EGR addition. The reason for this difference lies in the fact that $\mathrm{CO}_{2}$ and other EGR components are more concentrated as the engine approaches full load. Therefore, by increasing the load, the effect of EGR gets more significant. 


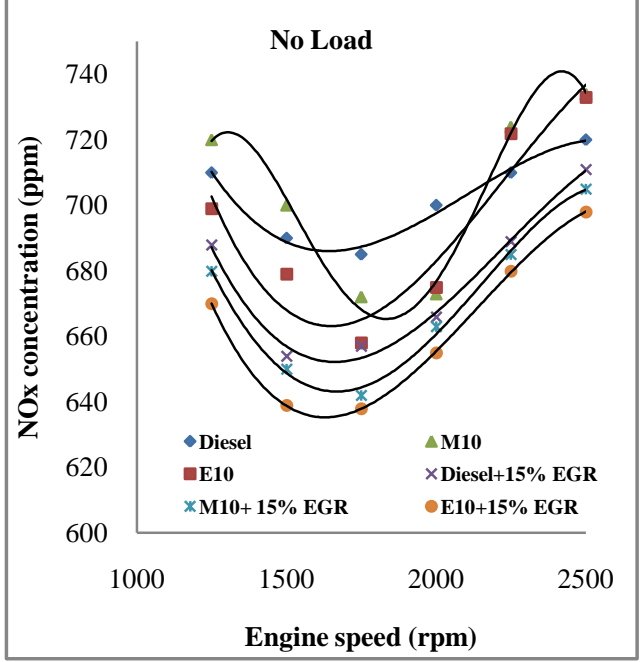

Fig. 3, Engine speed with no load effect on NOx concentrations with and without EGR for tested blends

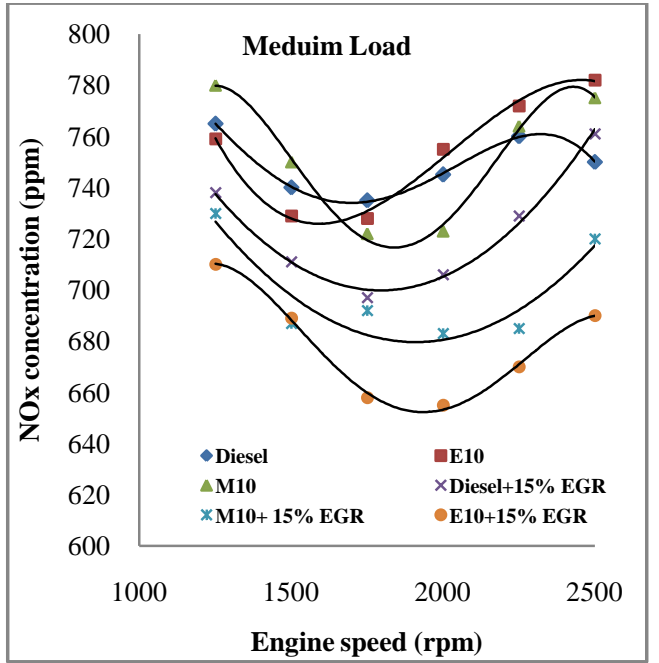

Fig. 4, Engine speed with medium load effect on NOx concentrations with and without EGR for tested blends

Under conventional diesel operation with high combustion temperatures the engine burns $99.5 \%$ of the injected fuel. When operating in lower temperature conditions (i.e., EGR addition), incomplete combustion can reduce the burn fraction to $95 \%$. This decrement causes an undesired reduction in fuel efficiency as combustion in not completed and fuel is left unburned which increase PM concentrations. Figures 6,7 and 8 represent the effect of load and engine speed on PM concentrations.

Ref. 27 demonstrated that the purpose of using oxygenated blend is to decrease the engine PM by providing extra oxygen for complete combustion. The results clearly showed that the engine PM could be decreased remarkably with the addition of oxygenates in diesel fuel under all conditions of various engine speeds and engine loads. This result is reasonable because the oxygenated blends could decrease the rich-spray region and increase the post-flame oxidation to the PM.

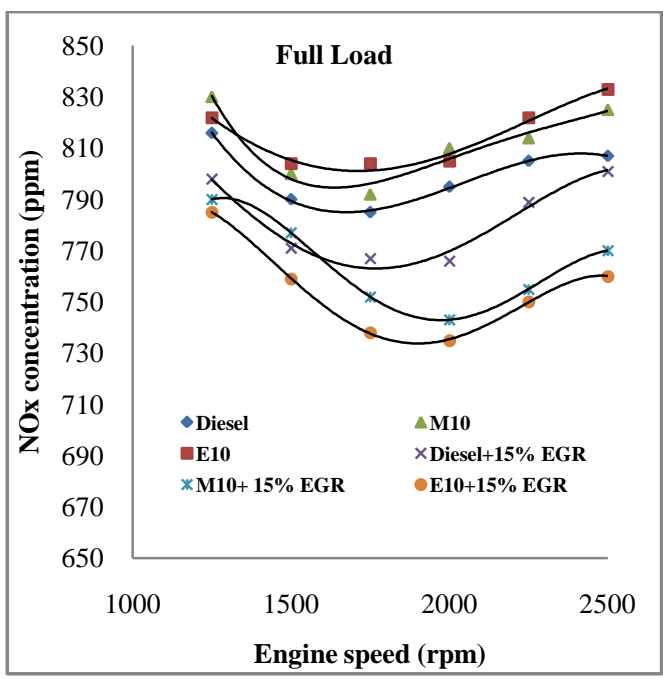

Fig. 5, Engine speed with full load effect on NOx concentrations with and without EGR for tested blends

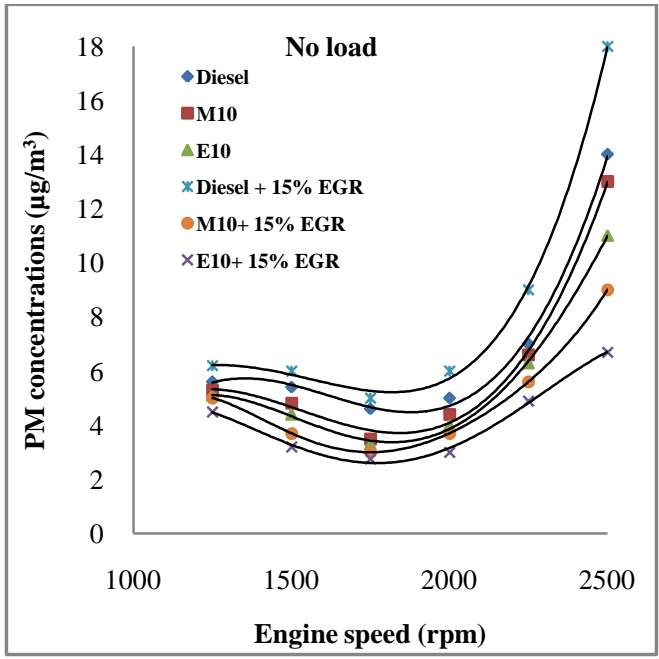

Fig. 6, Engine speed with no load effect on PM concentrations with and without EGR for tested blends

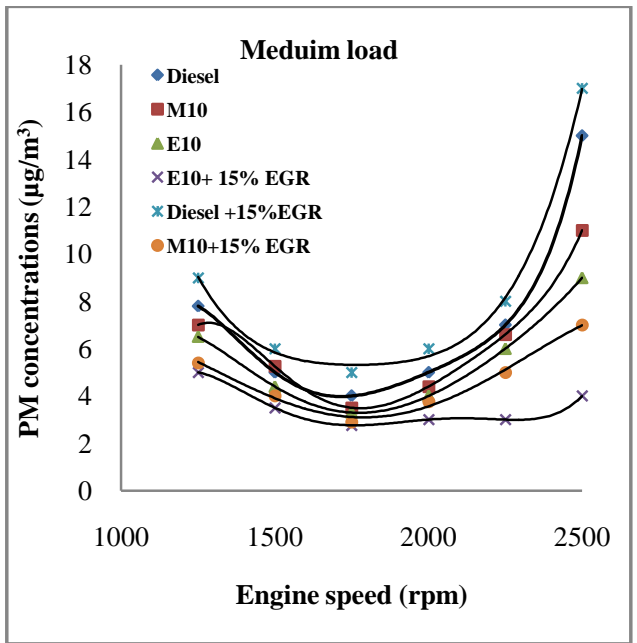

Fig. 7, Engine speed with medium load effect on PM concentrations with and without EGR for tested blends 
Oxygen enrichment from the oxygenated blends is helpful Fig. 9 depicts the equivalence ratio variation impact on the to improve the diffusive burning phase and PM reduction. NOx concentrations at mid load operation $\left(44 \mathrm{kN} / \mathrm{m}^{2}\right)$. The reduction of PM was determined to be more Near-rich equivalence ratios the combustion efficiency remarkable at high engine speed (between 1500 to 2250 deteriorated with EGR at $1500 \mathrm{rpm}$ - mid load. The $\mathrm{rpm}$ ), and this was also reasonable because the swirl with increasing EGR caused a reduction in the equivalence high intensity at these engine speeds improves the ratio, as Fig. 9 confirms, for all operating blends. A combustion chamber of the fuel-air mixing and reduce the excessive rich-spray region.

The NOx and PM relationship for the oxygenated blends from the above figures show a remarkable reduction in PM with oxygenating blends accompanied by the increase in NOx. The addition of EGR gives a simultaneous decrease in both PM and NOx.

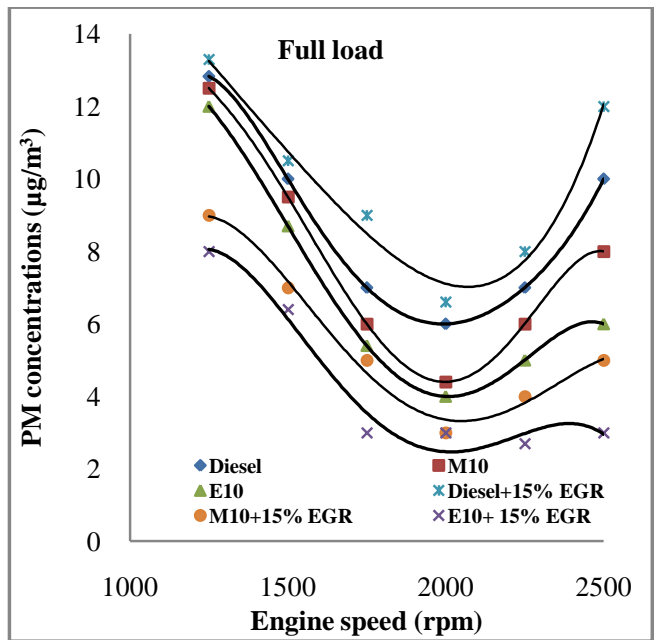

Fig. 8, Engine speed with full load effect on PM concentrations with and without EGR for tested blends

The combustion process and engine emissions depend on many important parameters as the fuel properties, initial pressure and temperature, the combustion chamber shape, and injection pressure. Another important factor called as $\varnothing$ implies to the equivalence ratio of the fuel. It is the one factor that decides whether an engine's combustion process is complete or incomplete and contributes to decreased engine emissions.

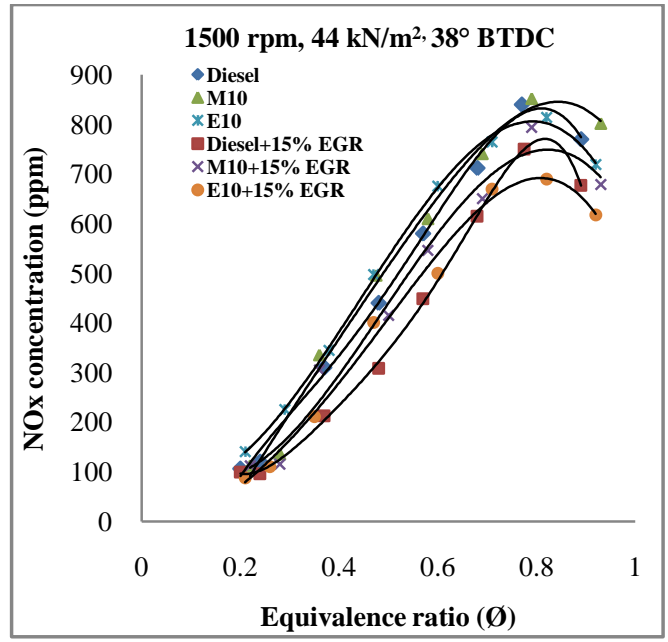

Fig. 9, equivalence ratio effect on NOx concentrations with and without EGR for tested blends decreasing equivalence ratio has a tendency to shorten ignition delay, as discussed before. The increased temperature and reduced equivalence ratio seem to clarify the dilution effect on ignition delay.

Fig 10 illustrates equivalence ratio variation effect on emitted PM concentrations. Particulate matter emissions decreased with increasing oxygenates concentration. PM emissions decreased from $17.3 \%$ for M10 to $21.68 \%$ for E10. The higher amount of PM in the exhaust observed when the engine operated with neat diesel and EGR compared to without EGR.

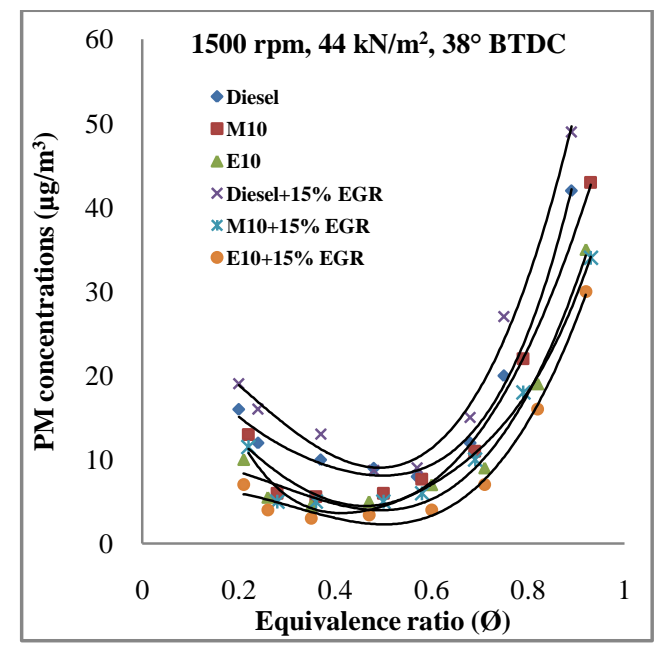

Fig. 10, equivalence ratio effect on PM concentrations with and without EGR for tested blends

PM emissions increased with increasing equivalence ratio. EGR reduces the oxygen availability for the complete fuel combustion, which results in relatively incomplete combustion and increased the formation of PM, although it reduces NOx emissions.

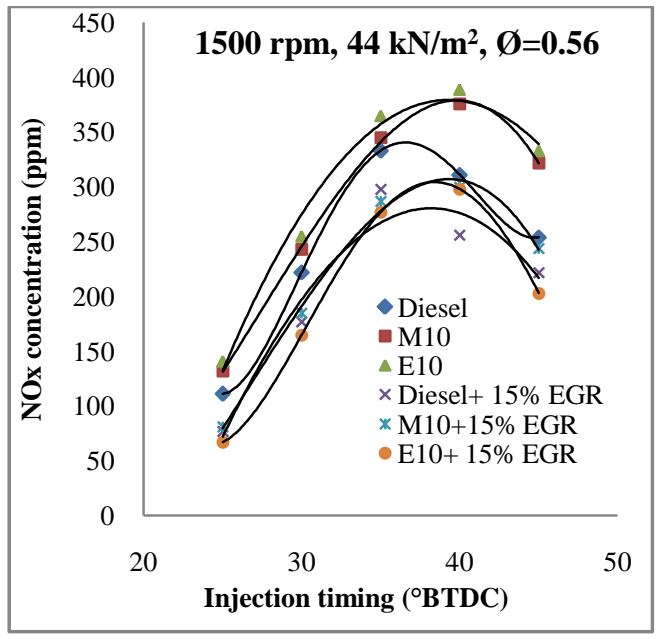

Fig. 11, injection timing effect on NOx concentrations with and without EGR for tested blends 
The utilization of ethanol and methanol increases oxygen content in the combustion chamber in a diesel engine, resulting in PM-decrease accompanied with an increase in NOx. Thus, oxygenated blends with EGR can be used to reduce NOx and PM simultaneously. Thus, an EGR addition with $15 \%$ with M10 and E10 considered as an optimal ratio.

The injection timing retardation is a powerful procedure for controlling NOx concentrations as Fig. 11 represents. Also, the existence of diluents such as $\mathrm{CO}_{2}$ and $\mathrm{H}_{2} \mathrm{O}$ in recalculated exhaust gas caused an increase in ignition delay and changed the location of the start of combustion. As a consequence, the whole combustion process moved toward the expansion stroke. This shift causes lower combustion products exposed to high-temperature conditions and accordingly lower nitrogen oxides formation.

Experimental results confirm that maximum cylinder pressure decreases when the EGR exists. Decreases in cylinder pressure peaks are dependent on the EGR ratios. Combined effects of fuels and EGR presented in the figure. Added EGR caused a reduction in NOx concentrations of about $16.8 \%$ for neat diesel. The reduction was about $22.91 \%$ with $\mathrm{M} 10$. The reduction percentage when E10 used was $29.5 \%$.

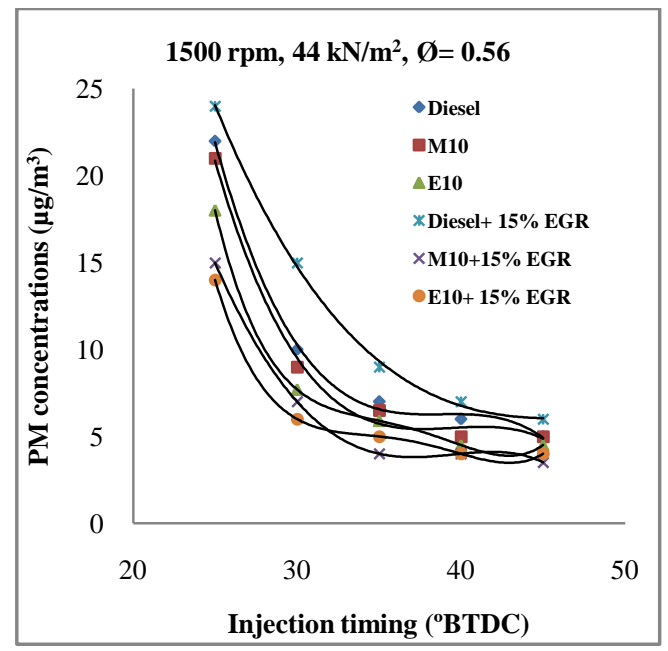

Fig. 12, injection timing effect on PM concentrations with and without EGR for tested blends

PM concentrations appeared a different behavior as fig 12 represents. Particulate matter emissions decreased with advancing injection timing. Increasing mixing time for fuel with oxygen reduced PM concentration. While reducing the oxygen concentration increases the mixing time of direct-injected fuel and fresh oxygen. The time increment intended to increase the ignition delay period and to decrease the burn rate once diffusion combustion starts. The EGR addition results in a reduction in the maximum heat release rate.

Other published literature achieved higher reductions in PM emissions compared to the findings of this work. Ref. 28 concluded that on average, the lower-sulfur, loweraromatic diesel fuel produces less particulate emission. Iraqi diesel fuel contains at least about 10000 ppm sulfur particles that are very high [29].

\section{CONCLUSION}

This experimental study presents the results of research on the influences of exhaust gas recirculation in combination with different alternative fuels and their diesel fuel blends on multi-cylinders engine NOx-PM emissions. The aim of the present study is to evaluate one of the approaches for achieving low NOx and PM emitted from a diesel engine by employing ethanol or methanol accompanied with EGR. Conventional Iraqi diesel fuel blended with ethanol and methanol for realizing the trade-off between NOx-PM emissions. The final results acquired are as follows:

1. It seems there is a trade-off between the effect of oxygen content of oxygenate blended fuel and the impact of its properties such as low heat value, low cetane number, low viscosity, high latent heat of vaporization

2. The oxygen content of ethanol and methanol blended fuel has the potential of decreasing the emissions especially PM due to their oxidation.

3. An optimum amount of ethanol-diesel or methanoldiesel blend is for a favourable NOx and PM emissions level depending upon ethanol and methanol purity and engine conditions.

4. As regard to NOx and PM emissions, there was found a general tendency. There existed variations depending on the operating conditions. Simultaneous reductions were registered at medium loads for the oxygenate-diesel blends when compared to neat diesel fuel. The actual decrease in PM emissions measured was slightly smaller than those reported in similar studies.

5. Compared to the conventional diesel fuel, the exhaust NOx reduced about $36 \%$ with $15 \%$ EGR due to less oxygen available in the recalculated exhaust gasses which lowers the flame temperature in the combustion chamber.

6. EGR constrained at high loads by the increase in PM resulting from reductions in air-fuel ratio.

7. The injection timing retardation reduced $\mathrm{NOx}$ and increased PM concentration, and an opposite behavior happened when injection timing advanced. In both situations, EGR with oxygenated blend caused a reduction in NOx and PM emissions.

\section{REFERENCES}

[1] C. Sayin, A. N. Ozsezen and M. Canakci, "The influence of operating parameters on the performance and emissions of a DI diesel engine using methanol-blended-diesel fuel," Fuel, vol. 98, No. 7, pp. 1407 1414, 2009.

[2] L. J. Wang, R. Z. Song, H. B. Zou, S. H. Liu and L. B. Zhou, "Study on combustion characteristics of a methanol-diesel fuel compression ignition engine." Proc Inst Mech Eng D - J Auto; vol: 222, pp: 619-27, 2008.

[3] Q L Phong, "Influences of alternative fuels and EGR on thermodynamic parameters and emissions of a heavy-duty engine," $\mathrm{Ph}$ D thesis, Hanoi University of Technology, 2007.

[4] G. Najafia and T. F. Yusaf, "Experimental investigation of using methanol-diesel blended fuels in diesel engine," Proceedings of the Fourth International Conference on Thermal Engineering: Theory and Applications, January 12-14, Abu Dhabi, UAE, 2009.

[5] M. T. Chaichan and K. I. Abaas, "Emissions characteristics of methanol-diesel blends in CI engines," Wassit Journal for Science \& Medicine, vol. 5, No.1, 177-189, 2012.

[6] M. Grahn, "Why is ethanol given emphasis over methanol in Sweden? "Course paper in the PhD-course, Energy, Environment \& 
Sustainability, Department of Physical Resource Theory Chalmers University of Technology, 2004.

[7] M. T. Chaichan, "Air pollutants and performance characteristics of ethanol-diesel blends in CI engines," Engineering \& Technology Journal, vol. 28, No. 21, pp. 6365-6383, 2010.

[8] B. A. Buchholz, R. W. Dibble, C. J. Mueller and A. S. Cheng, "Measuring the effect of fuel structure and blend distribution on diesel emissions using isotope tracing," Presented at Spring 2004 Meeting of the Western States Section of the Combustion Institute, Davis CA March 29-30, 2004

[9] Q. P. Le, "Influences of alternative fuels and EGR on thermodynamic parameters and emissions of a heavy-duty engine," $\mathrm{Ph}$ D thesis, Hanoi University of Technology, 2007.

[10] Y. Ren, Z. Huang, H. Miao, Y. Di, D. Jiang, K. Zeng, B. Liu and X. Wang, "Combustion and emissions of a DI diesel engine fuelled with diesel-oxygenate blends," Fuel, vol. 87, pp. 2691-2697, 2008.

[11] M. T. Chaichan, A. Q. Salam and S. A. Abdul-Aziz, "Impact of EGR on engine performance and emissions for CIE fuelled with diesel-ethanol blends," Arabic universities Union Journal, vol. 27, No. 2, 2014.

[15] M. Zheng, G. T. Reader and J. G. Hawley, "Diesel engines exhaust gas recirculation-a review on advanced and novel concepts," Energy Conversion Management, vol. 45, pp. 883-900, 2004.

[16] D. Agarwal, S. Sinha and A. K. Agarwal, "Experimental investigation of control of NOx emissions in biodiesel-fuelled compression ignition engine," Renewable Energy, vol. 31, pp. 2356-2369, 2006

[17] M. Ishida, S. H. Jung, H. Ueki and D. Sakaguchi, "Experimental analysis of thermal efficiency improvement due to high EGR ratio in HCCI engines fuelled with DME and natural gas," COMODIA, pp: 289-296, 2008.

[18] M. Ishida, S. Jung, H. Ueki and D. Sakaguchi, "Combustion characteristics of HCCI engines fuelled with natural gas and DME," 25th CIMAC, Paper No.171, 2007.

[19] T. Ohmura, M. Ikemoto and N. Iida, "A study on combustion control by using internal and external EGR for HCCI engines fuelled with DME," 2006 SAE Transactions, Journal of Engines, pp. 1043-1052, 2006.

[20] H. Ogawa, T. Li, N. Miyamoto, S. Kido and H. Shimizu, "Dependence of ultra-high EGR and low temperature diesel combustion on fuel injection conditions and compression ratio," SAE Paper No.2006-01-3386, 2006.

[21] T. Li, H. Izumi, T. Shudo, H. Ogawa and Y. Okabe, "Characterization of low temperature diesel combustion with various dilution gases," SAE, Paper No. 2007-01-0126, 2007.

[22] T. Li, M. Suzuki and H. Ogawa, "Effects of in-cylinder temperature and fuel-air mixing on smokeless low temperature diesel combustion," COMODIA Paper No.DE1-1, pp.135-142, 2008.

[23] Y. Ren, Z. H. Huang, D. M. Jiang, L. X. Liu, K. Zeng and B. Liu, "Engine performance and emission characteristics of a compression-ignition engine fuelled with diesel-dimethoxymethane blends." Proc Ins. Mech Eng Part D - J Automob Eng; vol.219 (D7), pp. 905- 914, 2005.

[24] N. Ladommatos, S. M. Abdelhalim, H. Zhao \& Z. Hu, "The dilution, chemical and thermal effects of EGR on diesel engine emissions Part 1: Effect of reducing inlet Charge oxygen," SAE Paper No. 961165, 1996.

[25] N. Ladommatos, S. M. Abdelhalim, H. Zhao and Z. Hu, "The dilution, chemical and thermal effects of EGR on diesel engine emissions - Part 3: Effects of water vapour", SAE Paper No. 971659, 1997.

[26] M. T. Chaichan, "The impact of engine operating variables on emitted PM and $\mathrm{Pb}$ for an SIE fuelled with variable ethanol-Iraqi gasoline blends," IOSR Journal of Mechanical and Civil Engineering (IOSRJMCE), vol. 12, N0. 6-1, pp. 72-79, 2015.

[27] M. Ghazikhani, M. E. Feyz and A. Joharchi, "Experimental investigation of the exhaust gas recirculation effects on irreversibility and brake specific fuel consumption of indirect injection diesel engines," Applied Thermal Engineering, vol. 30, pp. 1711-1718, 2010

[28] D. Checkel, E. Abdalgawad, J. Hawirko and R. Pryb, "Particulate matter emission profiles of Alberta heavy duty vehicles," Combustion \& Environment Research Group, Department of Mechanical Engineering, University of Alberta, USA, 2005.

[29] United Nation Environment Program (UNEP), "Opening the door to cleaner vehicles in developing and transition countries: The role of lower sulfur fuels", Report of the sulfur working group of the partnership of clean fuels and vehicles (PCFV), Nairobi, Kenya. 2007.

\section{BIOGRAPHY}

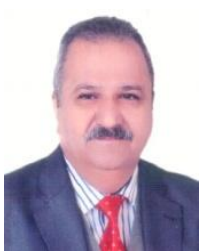

Miqdam Tariq Chaichan received the B.S. in Mechanical Engineering from Baghdad University in 1982 and M.S. degrees in Power Generation from University of Technology in 1989. Since 1999, he tough in several universities and investigated in many fields likes fuel and combustion, alternative fuels, Solar and Sustainable Energy. He is now Assistant Professor in Mechanical Engineering Dept., University of Technology; Baghdad, Iraq 